brane. He also discussed the idea that mitochondria may have developed from a symbiotic relationship between the cells and bacteria.

Professor W. M. Laetsch (University College, London) gave a comprehensive account of the life cycle of chloroplasts in higher plants and showed that etioplasts in tobacco leaves are capable of undergoing division. He emphasized the dynamic nature of chloroplasts and showed electron micrographs of chloroplasts in which the principal pathway of carbon dioxide fixation is into four carbon dicarboxylic acids; these showed membrane systems very reminiscent of the cristae in mitochondria and he alluded to the possible evolutionary relationship between the chloroplast and the mitochondrion. Dr R. Leech (University of York) described her study of the autonomy of chloroplasts in which she has tried to cause isolated organelles to survive and ultimately divide in vitro. She showed light micrographs of chloroplasts in culture that were apparently dividing.

Discussing the nature of nucleic acids in chloroplasts, Dr T. A. Dyer (Imperial College, London) presented evidence that chloroplasts contain $70 \mathrm{~S}$ ribosomes rather than the $80 \mathrm{~S}$ ribosomes characteristic of the cytoplasm, and said that evidence from inhibitor studies showed that the chloroplast DNA was chiefly responsible for the synthesis of structural proteins in the chloroplast. Drs M. L. Birnstiel and R. Wells (University of Edinburgh) described the use of biophysical techniques in the study of DNA isolated from chloroplasts and mitochondria. Their results show that DNA from lettuce leaf mitochondria is homogeneous, with a molecular weight of between 100 and $200 \times 10^{6}$. This is much higher than the molecular weight of DNA obtained from animal mitochondria. DNA from chloroplasts was not homogeneous and had a complexity some twenty times less than bacterial DNA.

\section{FRESHWATER BIOLOGY}

\section{Two New Keys}

VICTIMs of biting black flies will now be able to identify their assailants from a new Key to the British Species of Simuliidae (Diptera) in the Larval, Pupal and Adult Stages, provided, of course, they also have a binocular microscope. The booklet, by Lewis Davies, is published by the Freshwater Biological Association at $10 \mathrm{~s} 6 \mathrm{~d}$. The source is most appropriate because the larvae and pupae of black flies, or Simuliidae as they are properly known, are common in all types of freshwater, from trickles to large rivers. The adult females, however, are usually blood suckers, and on calm evenings in early summer can often be seen making life unpleasant for horses, cattle and domestic fowl.

Lewis Davies's key replaces one written by J. Smart in 1944, since when many more species have been found in temperate countries, largely through the efforts of taxonomists. The changes have been incorporated into the new key, which also has thirtyfour distribution maps showing where different species are found in Britain.

The Freshwater Biological Association has also published the third edition of Key to the British Freshand Brackish Water Gastropods $\left(\begin{array}{ll}4 s & 6 d\end{array}\right)$ by T. T. Macan. This key is already regarded with reverence by freshwater biologists who do not want a book which includes all the land snails, and they should be pleased to see the new edition with up to the minute corrections. Collectors are warned in the introduction that much of the confusion that exists today in snail systematics is a result of the excessive attention which has been paid to the shell rather than the soft parts.

\section{DRUGS}

\section{Aftucks on the liver}

\section{from our Medical Biochemistry Correspondent}

There is obviously little point in using a drug if the effects of treatment are worse than the condition being treated. The liver is often suspected to be the site of toxic effects, for many foreign compounds are metabolized in this organ. D. S. Platt and B. I. Cockrill (Biochem. Pharmacol., 18, 429, 445, 459; 1969) have recently made an extensive study of the effect of many drugs and other agents on the biochemistry of rat liver, and have shown that the response is complex and at present unpredictable.

They measured the effects of drugs on relative liver weight, microsomal and cell sap protein concentrations, and the activity of eight different enzymes or enzyme systems. The eleven distinct patterns of response showed that drugs produce many different changes in liver metabolism. The most important conclusion was that increase in size of the liver (hepatomegaly) is not a reliable indication of hepatotoxicity. The only similarity between agents causing hepatomegaly and established toxins was a decrease in the activity of glucose 6-phosphatase. The toxins (carbon tetrachloride, chloroform, 1,1,2,-trichloroethane, thioacetamide, dimethylnitrosamine and ethionine) all decreased the microsomal enzyme and protein concentrations whereas these increased in non-toxic hepatomegaly. This decrease in protein synthesis may be related to the decrease in plasma cholesterol esterification after treatment with carbon tetrachloride and ethionine as reported recently (M. Sugano, K. Hori, M. Wada, Arch. Biochem. Biophys., 129, 588; 1969). DDT (2,3 bis ( $p$-chlorophenyl) trichloroethane) and halothane (1,1,1-trifluoro-2-bromo-2-chloroethane), the toxicities of which are in dispute, gave biochemical changes similar to those produced by other drugs and, unlike the established toxins, supporting evidence against the toxicity of these compounds to the liver.

Related compounds usually gave identical response patterns, but chemically unrelated compounds, such as the barbiturates and DDT, could give the same response pattern. Liver enlargement was not necessarily associated with increases in microsomal protein or drug-metabolizing enzymes ; protein synthesis and the enzymes did not always increase together. Propanolol and the $\beta$-blocking agent ICI45,763 were metabolized by microsomal enzymes but showed no inducing effect, whereas barbitone and phenobarbitone had a very large inducing effect without appreciable metabolism. There was a very close correlation between increases in glucose 6-phosphate dehydrogenase activity and previously reported ability of the two drugs to produce hypertrophy of the smooth endoplasmic reticulum. The requirement of the drug-metabolizing systems for $\mathrm{NADPH}_{2}$ probably causes the increase in glucose 6-phosphate dehydrogenase activity. The range of biochemical effects observed is surprising and may be the cause of interactions between different drugs. 